\title{
Learning assistants as student partners in introductory physics
}

\author{
Patti C. Hamerski @ ${ }^{*}$ Paul W. Irving, and Daryl McPadden (1) \\ Department of Physics and Astronomy, Michigan State University, East Lansing, Michigan 48824, USA
}

(Received 12 February 2021; accepted 1 June 2021; published 13 August 2021)

\begin{abstract}
Despite the growing presence of students as partners (SAP) in education research and the overlap of goals with learning assistant (LA) programs, there is little research done on pedagogy- and curriculumfocused student partnerships that involve LAs. LAs have expertise as both teachers and learners, so why not leverage this expertise to improve the underlying structure and teaching philosophy of future offerings of a course? We intend to investigate this idea in the case of a flipped, introductory physics course at Michigan State University by conceptualizing its LA program as a model for enacting SAP using the communities of practice (COP) framework. Using an interpretivist case study approach, we found in this environment that (i) the LAs experienced a learning trajectory within P-Cubed that resembled attainment of central membership in a COP, (ii) the development of a specific practice among LAs resembled the evolution of practice in a community of practice, and (3) LAs have a strong level of influence over decision making on curriculum and pedagogy in P-Cubed in a way that is indicative of authentic student partnership. This input is particularly important for a specific type of partnership: curriculum design and pedagogic consultancy, which requires significant participation and say so from LAs. Reconceiving LA programs as student partnerships opens a path to incorporate students into and reinforce sustainable curriculum change.
\end{abstract}

DOI: 10.1103/PhysRevPhysEducRes.17.020107

\section{INTRODUCTION AND BACKGROUND}

The curriculum design process traditionally exists in the hands of expert instructors and practitioners, outside the influence of students themselves. Recently there has been a push to acknowledge and encourage the development of partnerships between students and instructors, where students are consulted, for example, on improving teaching practice and curricular materials. The recent focus of education research on students as partners (SAP) is marked by the launching of a journal dedicated to the topic as recently as 2017 [1]. SAP has been conceptualized by Healey et al., [2] as a "partnership learning community" that can take on four different, overlapping forms: (i) students facilitating the learning, teaching, and assessment, (ii) students conducting subject-based research and inquiry, (iii) students consulting on curriculum design and pedagogy, and (iv) students learning about and enhancing the quality of teaching and learning. This study will focus on a specific case of the third type of partnership-namely, how a community of practice of learning assistants (LAs) in an introductory physics course led to a sustainable student partnership that influenced course structures.

*patti@msu.edu

Published by the American Physical Society under the terms of the Creative Commons Attribution 4.0 International license. Further distribution of this work must maintain attribution to the author(s) and the published article's title, journal citation, and DOI.
Typically, the work of conceptualizing partnership learning communities involves comparing them to the communities of practice (COP) framework [3]. For instance, Healey et al., [2] contrasted and aligned SAP with COP. They argued that like in COP, student partnerships are composed of apprenticeship-like relationships where newcomers (i.e., students) learn from old timers (e.g., faculty) by engaging in practice together. Both models emphasize a shared enterprise or goal that members of the partnership or community work towards together. The partnership also involves a learning trajectory much like in a COP, where the student learns what goes into teaching (or other practice) behind the scenes, and comes to make their own contributions to the practice as they gain expertise and offer their own input.

That said, there is a significant difference between COP and SAP in how members are recruited. In COP, new members of a community join by forging relationships with existing members and aligning their participation with the goals of the community. In a partnership learning community, "it may not be enough to simply extend invitations for new partners to become part of existing communities. In these new communities all parties actively participate in the development and direction of partnership learning and working and are fully valued for the contributions they make" [2]. The contrast between who is responsible for facilitating the development of relationships in the community indicates that faculty who wish to use student partners must be willing to work hard at forging partnerships.

Effort towards student partnerships must also be focused. Matthews [4] highlights three tenets that make a good 


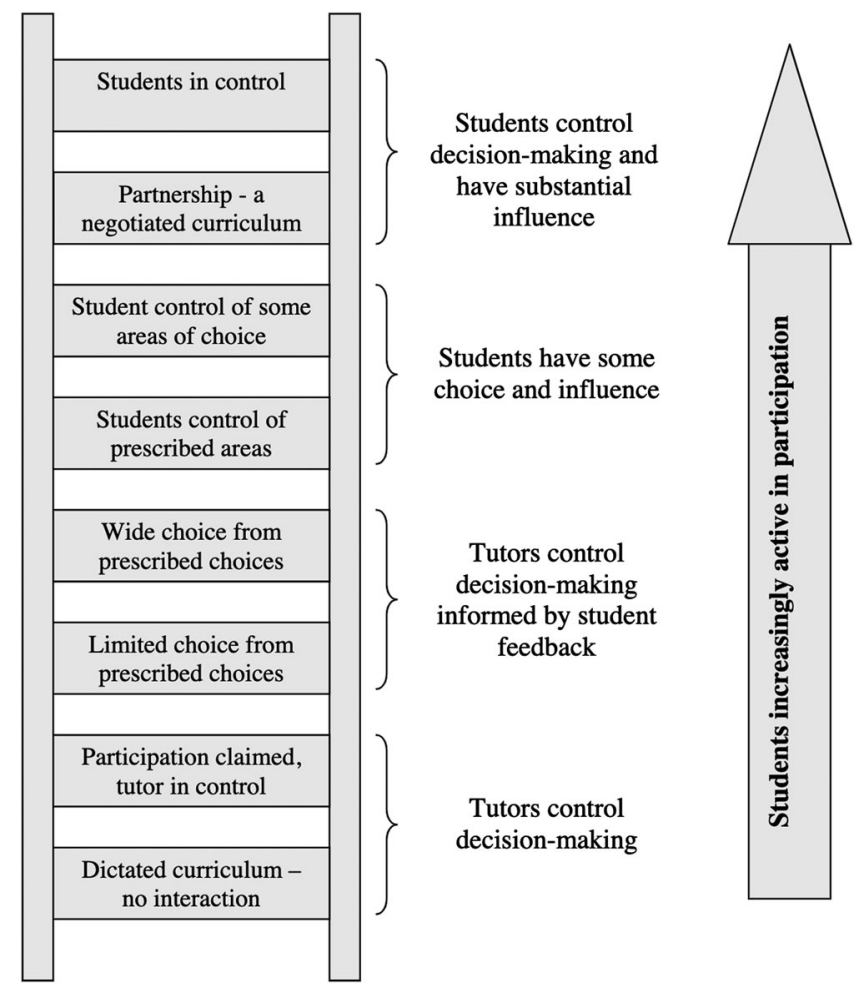

FIG. 1. LA participation ladder: a visualization of the different levels of influence that LAs can have on curriculum design and pedagogy. Borrowed from Bovill and Bulley [6] to conceptualize student-faculty relationships instead of student-tutor relationships.

student partnership. First, the relationship between teacher and student must be reciprocal, meaning all members of a partnership must give input and have their input valued. Sohr et al., [5] warned against a troubling pattern where student voices get tokenized without being incorporated, so that an institution might posture at having student partnerships in place. Second, the goals of a student partnership must be good morally, meaning all parties benefit: faculty, students in the partnership, and other parties impacted by the partnership. Third, the outcome must strive for broad (beyond individualistic) change. For example, a partnership that changes the structure of a course in a sustainable way would achieve this outcome, whereas a temporary impact on a handful of students would not.

With these tenets in mind, SAP can still take many forms with varying levels of student involvement. To illustrate the variety, we have adopted a visualization of the "participation ladder" from Bovill and Bulley [6], as seen in Fig. 1. The ladder was originally used to describe the relationship between students and tutors in an active learning environment, but has been repurposed [2] to describe the strength of impact in partnerships that are focused on curriculum design and pedagogy. The bottom rung of the ladder represents a curriculum that is completely in the control of the faculty member with no input from students. On the opposite end, the top rung of the ladder represents students in complete control of the curriculum. The rungs in between represent the different levels of balance between student and faculty control in the course.

The SAP literature reflects this variation. Bovill [7] emphasized that although authentic student-staff partnerships are usually high up on the ladder, "co-creation is not about giving students complete control, nor is it about staff maintaining complete control over curriculum design decisions." She argued for reciprocal roles between faculty and students, even at the top of the ladder. As an example, she described a course where the tutor or faculty guided the students in designing their evaluation exercise for the course, gathering feedback, and compiling recommendations for the course from the students themselves. In this case, the student control over the evaluation process places this partnership on the top two rungs. Flint and O'Hara [8] described a body of student representatives who sit on university governing committees that incorporate the voice of students into institutional decision making. Because of the history of newer student members outnumbering other students in the governing body, the students tended to have limited influence on what the committees oversaw, placing this partnership on the third or fourth rung from the top. Sohr et al.,[5] described students who were recruited and interviewed to help redesign a quantum mechanics class. Because of the tutor facilitation of meetings where students gave input, and the tutor-led synthesizing of feedback, this partnership would likely exist on the fifth or sixth rung of the ladder, based on the iteration described in the research. Mercer-Mapstone et al., [9] reviewed and analyzed 58 papers on SAP to show that most of these partnerships focused on changing curricular materials in a course or altering teaching strategy. These partnerships were often forged informally by professors who wished to incorporate student perspectives but did not have the means to do so outside of asking students to meet with them and provide their input. From these examples, the reality of researched partnerships is that they tend to center students who do not teach and who operate within small-scale, unpaid partnerships.

An alternate model for utilizing students in the classroom is the LA model. Over the last two decades, LA programs have become an ever-growing feature in undergraduate programs across the country, particularly in science, technology, engineering, and mathematics (STEM) disciplines. Initially conceived at the University of Colorado Boulder in 2003 [10], LA programs have since spread widely in varying forms [10-14]. The premise behind an LA program is to hire undergraduate students as LAs to facilitate learning in the classroom. The common goals of LA programs revolve around improving undergraduate courses, helping students improve their teaching practices, 
and recruiting undergraduate students into the teaching profession. While these goals are distinct from those of student partnerships, there are some overlaps, especially in trying to improve undergraduate courses. In most of the LA programs that have been discussed in prior research, LAs fulfill three duties: teaching students in a class, attending meetings for class preparation and planning, and taking a pedagogy course or teaching seminar with other LAs [10,1217]. Within physics, many active learning curricula, including SCALE-UP [18], University Modeling Instruction [19], Interactive Science Learning Environment (ISLE) [20], and Washington Tutorials [21], have been implemented in conjunction with LA programs to facilitate small group discussions and learning at the scale required for university courses.

Previous research on LAs tends to focus on the benefit LAs bring to student engagement and learning rather than to structural components of the course. For example, the presence of LAs in STEM courses has been shown to improve student learning gains on conceptual inventories [10]. The same study demonstrated that LAs also improved students' attitudinal gains compared to non-LA courses, and they increased the instructors' attention to student learning while planning for class. An extensive study [22] on instructor effectiveness-a quantitative measurement of collective student learning ascribed to instructors over multiple semesters-found that LAs helped instructors maintain their effectiveness, whereas, without LAs, the instruction declined from year to year (even when controlling for flipped vs lecture style and previous teaching experience). Several studies have confirmed the benefit that LAs have on the grades and passing rates in student performance within the same courses [12,23,24], and in some cases especially for students from underrepresented backgrounds [25]. Thus, there are strong motivations from research to include LAs in the classroom, from improving student learning outcomes to improving teaching effectiveness.

Despite the growing presence of SAP in education research and the overlap of goals with LA programs, there is little research done on student partnerships that involve LAs. Jardine [26] researched student-faculty relationships in undergraduate biology courses, where LAs were asked for feedback on course structures by the faculty members during meetings. The goals of these questions were to redirect how course materials were drafted up and how exams are graded, all ultimately at the discretion of the faculty. This reduces the amount of influence held by LAs since the only mechanism for change was filtered through the faculty members. Other research highlighted LAfaculty relationships but did not analyze with a partnership lens. Sabella et al., [15] demonstrated how LAs were used in a physics course to shape and improve curricular materials on a semester-by-semester basis, but they did not use the SAP framework or extend to broad, sustainable change to the course as outlined by Matthews [4]. Other research on the impact of the LA experience on the LAs themselves $[16,17,27,28]$ highlights how LAs grow as people during the experience. For example, Close et al., [13] described how these LAs' identities shifted during their time as LAs using the COP framework. However, that work focused on the individual LAs and did not detail the impact of the LA partnerships on the course structure. In some studies $[27,28]$, the impact is described on the basis of how the faculty member benefited from working with LAs, but again the influence does not seem to extend beyond the individuals directly involved.

This previous research highlights a disconnect between COP, SAP, and LA programs. However, it also offers the opportunity to reimagine LA programs at that intersection. We propose that LAs in P-Cubed effectively occupy the "student" role in SAP, taking precedent from Jardine [26]. Undergraduate LAs have expertise as both teachers and experienced students, so why not leverage this expertise to improve the underlying structure and teaching philosophy of future offerings of the course? Through this study, we intend to contribute to this idea by conceptualizing a specific LA program as a model for enacting SAP using the COP framework. In the following section, we outline the course context for the specific LA program.

\section{A. P-Cubed}

In examining a LA program with a student-partnership lens, we focus this study on one group of LAs at Michigan State University (MSU) who work in a flipped, introductory, calculus-based mechanics course offered in the physics and astronomy department called Projects and Practices in Physics (P-Cubed) [29]. LAs for the course have three primary obligations: (i) facilitate in-class group work and problem solving by acting as a tutor who guides but does not give answers, (ii) attend pre- and postclass meetings to prepare for class and reflect on how it went, and (iii) write individualized, weekly feedback aimed at improving students' scientific practices. The third duty listed is different from many other LA programs that research has covered in the past, which often do not have an individualized written feedback component.

The problem-based design of P-Cubed means that students review material outside class and solve smallscale problems for homework. When they come to class, students are arranged in groups of four or five, and together they solve a single open-ended physics project that takes $2 \mathrm{~h}$ to work through. Each group has a LA or other instructor assigned to it (75\%-80\% of the instructional staff is LAs), with each instructor responsible for 2-3 groups of students. The instructor's role is to guide the problemsolving process and to encourage collaboration and creativity, as there are many ways to solve each project. During class, the instructors also make observations for each of their students, which then can be used to construct feedback each week. This written feedback allows the group's 
instructor to reflect outside of class, address any issues from the class, and make suggestions for improvement in the next week. Instead of grading each problem for correctness, students are graded on their approach, process, and collaboration with their group. In a given week, LAs attend two preclass meetings to prepare for each class period's physics project and one postclass meeting after both class periods to reflect on the week together and trade advice on teaching and/or writing feedback.

The P-Cubed course has several features that make it an ideal context for our investigation. First and foremost, the course was originally designed from a COP perspective $[29,30]$. When the course was conceived, the developers decided to focus the goals of the course on developing certain practices aligned with the communities of undergrad physicists and engineers, who were most likely to represent the students in P-Cubed. To make these practices authentic, the designers intentionally made the problems ill structured and underdefined so that students would be forced to engage in solving these problems using authentic means. This means students would have to negotiate the meaning of the problem and tackle complex and intricate issues collaboratively, which in turn facilitates engagement in multiple scientific practices. While it is unclear how to design a community of practice from the ground up explicitly, it is possible to create structures and opportunities that would allow a community of practice to develop [31]. Second, as a part of the COP design, LAs were intentionally positioned as intermediate members of the COP by the course developers [30]. Because LAs are simultaneously positioned as both peers and experts, they offer a pathway into the center of the P-Cubed community. LAs are a living bridge between the student experience and the instructor experience, so they represent the learning trajectory that members of a COP can travel to achieve centrality. This trajectory was designed to be a guided experience through the use of the P-Cubed feedback mechanism (a direct link for students to learn from more central members of the community).

Our first goal then for this paper is to demonstrate that a community of practice has indeed formed in the P-Cubed course.-This is an important first step since a community of practice is not a guaranteed outcome based solely on design decisions. From there, we will show how LAs have directed and influenced one particular practice in the course -namely, constructing feedback. We choose to focus on feedback rather than other practices for three main reasons: (i) The practice of feedback is outlined and described in detail in the course materials which were written upon inception of the course. This makes it easier to discuss how the LA practice of feedback has evolved over time and taken shape based on LA experiences combined with the original course design. (ii) Because of the regular nature of feedback writing and the ease with which LAs can share their written feedback among one another, it is a practice on which LAs tend to advise one another more heavily compared to other practices. (iii) Feedback is an opportunity for LAs to infuse their own expertise into the course because LAs have the freedom to write about what they deem important to succeeding in P-Cubed. They also get to decide what it means to write good feedback when they advise one another on feedback-writing throughout the semester. For these reasons, the practice of constructing feedback exemplifies the community aspect of LA duties and the trajectory that practice can take when under the influence of central members of the community of practice.

Our second goal is to show how the LA community of practice can be viewed as a student partnership in the course.-This is a unique perspective and adds to the SAP literature because of the unique trajectory LAs take within the P-Cubed community and the opportunities they have to infuse their expertise into the P-Cubed curriculum. Their trajectories are special because P-Cubed LAs are recruited when they are students in the course, so they have experience both as students who took P-Cubed and as instructors.

To that end, we aim to answer the following research questions in this paper: (i) Has a community of practice developed around LAs in P-Cubed? (ii) How has the practice of feedback been shaped by P-Cubed LAs? (iii) How can the LAs' influence be characterized as a student partnership, and what characterizes this partnership and its outputs?

To answer these questions, we will first dive into the details of what comprises a community of practice and how the LAs in P-Cubed could be viewed and analyzed from this perspective in Sec. II. We will then describe our case study approach to the LA community and how this approach helped us select and analyze our data sources in Secs. III and IV. In Sec. V, we will present the results of the case study and answer the research questions above. In Sec. VI, we will discuss the implications of having an LA model that begins with a COP design and has developed into a community-based partnership.

\section{THEORETICAL FRAMEWORK}

We use the theory of COP [3] throughout this paper to describe and analyze the community of P-Cubed LAs. By definition, a community of practice is a group of people who share common goals and work together using shared practices to achieve them. The goals are communally negotiated and evolve over time. Practices are patterns of activity that have been agreed upon over time and developed as cultural norms among the group. Learning in a community of practice happens when a member comes to participate in ways aligned with the shared practices and shared goals of the community. Historically the "center" of the community, or the goals and practices to which new members align their participation, shifts as central members leave (reduce participation) and new members join and negotiate their participation in relation to their own experiences and personal histories. We intend to use this theory 
of participation and learning to demonstrate that the LAs have formed a community of practice and how that community of LAs took up the specific practice of feedback writing, made it their own, and wielded influence over other aspects of the course in a partnershiplike way. In the following sections, we introduce $\mathrm{COP}$ as laid out by Wenger [3] and then show how we conceptualize the design of P-Cubed as an environment that encourages the development of a community of practice.

\section{A. Communities of practice}

Etienne Wenger developed the learning theory of COP [3] as a follow-up to Jean Lave and Etienne Wenger's situated learning [32], which expanded on the apprenticeship model to address the idea of learning as legitimate peripheral participation. In COP, Wenger drew primarily from situated learning but provided more details on what it means to learn in a community of practice and framed learning in terms of a duality between practice and identity. For this study, we focus primarily on Wenger's conception of practice, which he viewed in terms of five mutually defining and deeply connected features: negotiation of meaning, community, learning, boundary, and locality. For our theoretical framework, we focus on the negotiation of meaning, community, learning, and boundary. Locality was important for our research design and methodological choices, but did not factor heavily into our findings and implications. For this reason we focus our theoretical framework on the other features, but still provide a description of locality in the next section to demonstrate how it could theoretically contribute to the development of a community of practice.

Negotiation of meaning takes place in the duality of two member-driven processes: participation and reification. Members participate in practice by directly engaging with other members and actively carrying out the goals of the community. This participation ties to how they reify, or "form to experience by producing objects that congeal this experience into "thingness" (p. 58) [3]. We can see the interlocked nature of these two processes when considering how reification is brought about by historical patterns of participation. For example, physicists often draw a free body diagram to help visualize the forces at play in an introductory mechanics problem. The setup of the diagram is not by nature a representation of forces. However, it is widely interpreted that the simplified free body and the straight arrows represent forces because of how participation patterns over time in introductory mechanics have reified forces on an object into a free body diagram. As Wenger puts it, "what is said, represented, or otherwise brought into focus always assumes a history of participation as a context for its interpretation. In turn, participation always organizes itself around reification because it always involves artifacts, words, and concepts that allow it to proceed" (p. 67) [3].

Community refers to the members themselves and their relationships with one another [3]. It also refers to their relationship with the context of the shared practice. A community consists of three dimensions: mutual engagement, joint enterprise, and shared repertoire. Mutual engagement in a community is marked by the togetherness of the practice and the relationships that exist between members. Meaning is negotiated between members, not on an individual basis. Joint enterprise in a community exists because members have mutual accountability to one another in carrying out the practice in a way that advances the cause of the community. The enterprise is joint in that it is mutually constructed and agreed upon together. Shared repertoire is (i) the set of routines, tools, words, actions, or concepts that the community has reified over time and (ii) the ways through which these resources become a part of how community members engage in practice. We connect these three dimensions through their mutual involvement in how members negotiate meaning. For example, on a volleyball team, members need to interact constantly (mutually engage) in order to convey where the ball should be hit and who should prepare to return the ball to the other side. There may be compromises between varying interpretations of goals (joint enterprise) - some members want to have fun while others focus more on winning. Even among these goals, there are varying interpretations of how to achieve them. The shared resources (repertoire) of the team can help facilitate pursuits of the enterprise and the gameplay such as recognizable shouts of "mine!" between players to signal intent, techniques for setting the ball in a desirable spot, or announcements of the score before each serve.

Learning refers to a trajectory that involves aspects of both negotiation of meaning and community [3]. Members of the community traverse the trajectory by participating and reifying as described above. When members participate, they remember and forget aspects of the experience, and their memories change over time to embody how they view the relevant practice. In the same way, they reify artifacts when they participate, and these artifacts preserve the history of practices. Because of the choices that are embedded in reification and the selectiveness of memories, members come to view practices in new ways and they gain experience with doing practices in such ways. The practices themselves can change too, as more central members develop new perceptions and ways of doing things based on the choices packed into reification and memory. This process defines learning. Newcomers to the community invariably must learn the practices, and they embark on this trajectory by participating (forming selective memories) and reifying (preserving their participation). Importantly, this is a community process, because newcomers would not know how to participate without mutual engagement, and they would not know how to reify without a shared repertoire that they can dip into. As they move closer to the center from the periphery, their practice transitions from learning from others to learning where the practices of the community are headed (and influencing their direction). 
Boundary emphasizes the ways that participation and reification can connect communities and create a sense of continuity between their practices [3]. Members of multiple communities can act as brokers by translating elements of practice across contexts through their participation in those communities. The focus lies with participation of brokers because of the active role brokers play in understanding how practices are connected and introducing and facilitating modes of participation from one community to another. An example of a broker is a high school track coach who draws on her experiences networking with other coaches at track meets to teach running techniques to her student athletes, thereby relaying participation from her coaching community to her high school track team community. Reification can also serve as a robust intercommunity connection, which Wenger described using the term boundary object. We often refer to instances of reification as "objects," but when they belong to multiple practices, "they are a nexus of perspectives and thus carry the potential of becoming boundary objects if those perspectives need to be coordinated" (pp. 107-108) [3]. For example, the act of making possible and enabling the production and distribution of a band's music could be reified in a recording studio, but that studio is also used as a place of work for sound engineers and technicians. The studio is a boundary object because these different communities (band members, technicians) use it to come together and coordinate their perspectives and practices.

\section{B. The design behind the development of a community of practice in P-Cubed}

In thinking about how the burgeoning community of LAs in P-Cubed could embody the features of a community of practice, it is helpful to discuss how negotiation of meaning, community, learning, and boundary are designed into the course. For the purposes of this paper, we will focus our examples around the practice of writing feedback; however, we recognize that this process could also occur for the other practices designed into the course. First, we will address the negotiation of meaning, which, at its core, is the duality of participation and reification. When we think of how LAs are meant to engage in participation, we envision discussions that are encouraged during postclass meetings about how to address student behaviors in feedback, interactions with students in the class, and the processing of LA-jotted in-class notes into the feedback itself. When we think of how LAs are meant to engage in reification, we envision how they use the assessment guide in deciding how to frame their feedback. Phrases like "group understanding" (the title of an in-class assessment category) can be used to communicate to students and other LAs about in-class observations. LAs also need to interpret whiteboard scrawlings during class to understand where their students got stuck. The ways that LAs are meant to participate and reify in their feedback-writing practice are necessarily interlocked, and these processes together are how LAs negotiate meaning - without them there would be no point in writing the feedback, and its contents would not be meaningful to the students if not based on in-class observations and LA-written notes. When extended out to other practices that LAs could have influence on, we look at negotiation of meaning from a SAP perspective, which puts lasting, structural impact into focus. This highlights that structural influence often takes the shape of reification, a process that produces artifacts for future community members to shape their own practice around.

The LA program in P-Cubed is also designed to form a community (the second feature of practice). We envision mutual engagement among LAs in discussions between LAs on feedback writing during postclass meetings, relationship building through shared coursework and studenthood, and the helping out that happens when LAs ask one another to review their written feedback. For LAs who write feedback, the joint enterprise would be focused on the goal of helping students improve their scientific practices and group work through the process of writing individualized feedback for them. The reasons for LAs to review one another's feedback would include not only the relationships that exist between LAs but also their understanding that the improvement of any LA's feedback is an advancement of the joint enterprise. The shared repertoire of feedback writing includes in-class note taking, the act of writing the feedback itself, the norms of interaction during postclass meetings, and the shared historical experience of having been a student in P-Cubed. Because the design of PCubed encourages the collective experience described, we aim to explore how LAs can have a powerful collective impact within the potential student partnership that we will investigate.

Third, the learning trajectories of LAs and of the community itself ideally begin when LAs are students in the class. The P-Cubed feedback and in-class teaching practices are meant to onboard students with collaborative skills and an understanding of what it takes to be an LA. Students who are recruited into the LA program would be positioned as "newcomers" in the community. Newcomers learn by aligning their participation with more senior members of the community, which in the case of PCubed would mean that LAs would collaborate by consulting one another on feedback and by asking one another for help teaching during class when issues arise. As LAs gain teaching expertise and travel along their own learning trajectory, they would also start to gain influence over the direction of the practice. Over time, practices would evolve similar to how we would envision the impact of a student partnership. Learning trajectories are where we would look to in order to examine whether the SAP model can be applied to P-Cubed.

Fourth, the boundary of the P-Cubed LA community can be illuminated by its brokers and boundary objects. LAs could act as brokers by drawing on outside experience to 
bolster their teaching and feedback practice-some LAs would have received vivid and helpful feedback when they were students in P-Cubed, which they might translate into constructing feedback today. Others study physics or engineering in upper-level classes, from which they can draw to provide a more in-depth perspective on some of the physics concepts for their students. An example of a boundary object is old feedback that a LA received as a student. When they first received it, it served to help them improve their scientific practices and group work, which advanced their learning as a P-Cubed student. Now, as a PCubed LA, they can repurpose the old feedback to help them understand what could be helpful for a current student to hear. Even though the LA's involvements in each community are separated by time, the boundary object (old feedback) reified past participation (e.g., group work) in a way that has allowed the LA to access and translate it for use in the current practice of feedback construction. This exemplifies one of the ways LAs have personal influence on P-Cubed practices, which could be viewed as an instance of LAs leveraging their power in a student partnership.

The other feature of practice (locality) is also relevant, though we did not describe it in detail because it does not serve our finalized investigation in significant ways. To summarize its presence in the design of P-Cubed, locality refers to the unit of analysis of the community of practice. We could have expanded the scope (locality) of our investigation to focus on the entire class of LAs and students, or we could have narrowed to a small group of LAs that meet for preclass meetings together. We chose to view the LAs and other instructors as a single community or "unit" because this is what allows us to most easily discuss the varied perspectives of LAs and how those perspectives trace their roots and evolve.

\section{METHODOLOGY}

By focusing on the LA and faculty perspectives in this work, we choose to take up an interpretivist lens [33] on the case study. This means we adhere to the idea that we use case studies for seeing how participants socially construct a phenomenon and what it means to them as participants. In this investigation, the phenomena encompass the relationships between instructors (LA-to-LA and LA-to-faculty) and the relationships between LAs and teaching practices. The case itself is the P-Cubed environment. The interpretivist stance is helpful for our study because it helps us leverage the participants' perspectives on the phenomena, which are centered around LAs and their function-what matters to us is not the essence of P-Cubed's LA program (if there exists such a distillation), but rather how LAs experience it.

We chose to generate most of our data from interviews with LAs and a faculty instructor. The reason for this is that we treat each interview as a separate "anchor point" [33] from which we can view the phenomena of interest. By collecting perspectives from multiple insiders on this process, we intend to triangulate their interview comments when we build our own understanding of the LAs' perceptions of the phenomena. We describe the interviews and other data sources in greater detail in Sec. IV. Our interpretivist stance motivated us to choose data sources that represented the LA-to-faculty perspectives on the community within P-Cubed, of which they are members.

In a prior study [34] on LA feedback in P-Cubed, we focused on how LAs transferred practices and skills from their experience in feedback construction to other academic settings. A main finding for one LA was that the feedback mechanism played a big role in making her LA experience meaningful, as well as helping her manage her academic studies in other contexts. The depth of the relationship between the feedback mechanism and this LA's academic life pointed to the boundary-crossing that happens when LAs learn to use their teaching expertise in other areas of their lives. This process is part of what happens in and out of a community of practice, and our research questions in this investigation focus on characterizing this community of practice, highlighting how LAs have impacted the practice of writing feedback, and understanding how the LA-centered student partnership is reflected in other PCubed processes.

We chose to bound our case to the experiences made known to us through interviews, emails, and written course artifacts like feedback and course materials, because we sought to compare the experiences and artifacts that most closely related to the feedback construction process. These glimpses into the lives of LAs and instructors gave us a unique view into the functioning of P-Cubed's teaching staff that only the practitioners could give. By investigating how a feedback mechanism like the one in P-Cubed functions in the hands of LAs, we intend to demonstrate how the practice of constructing feedback has developed under the influence of LAs, and how that influence points to the dual existence of a community of practice and a student partnership. When LAs allowed us to step into their world to see what they value and practice as a community, we were able to demonstrate what this community of practice and partnership looks like and how it functions.

\section{METHODS}

Our analysis focuses on interviews with three P-Cubed LAs as the primary data source. We also sought alternate angles on the feedback mechanism by gathering written feedback excerpts from the interviewed LAs to cross reference with their interview comments, interviewing a P-Cubed teaching faculty, and collecting artifacts from the semiannual LA training where new and old LAs convene to be trained by Irving and McPadden on constructing feedback, among other things. We display the complete set of data in Table I. We found that the LA interviews provided 
TABLE I. Five types of data sources: interviews, feedback, course documents, discussion notes, and emails.

\begin{tabular}{ll}
\hline \hline & \multicolumn{1}{c}{ Data sources } \\
\hline Individual interviews & Four semi-structured interviews: three with LAs; one with faculty \\
Feedback & Forty written feedbacks from each LA (120 total) \\
Course documents & Assessment guide; presentation from training \\
Notes & One set of notes jotted during LA group discussion during training \\
Emails & Written email correspondence with two LAs after interviews \\
\hline \hline
\end{tabular}

the most profound insights, which is reflected in how we showcase our analysis.

We conducted interviews in a semistructured manner. The original protocol was developed using Patton's methods [35] to address earlier research questions about how the feedback mechanism influenced LAs' academic lives. As the angle of our research shifted in response to interview comments, so too did the interview protocol. In this way, we developed the protocol iteratively. The artifacts and feedback excerpts were gathered directly from LA training and the course archives. When the focus of this case study became the influence LAs wield upon P-Cubed teaching practices, we generated additional data. First, we gathered email exchanges with the interviewed LAs where they described how their roles changed over the course of their LA tenure. Second, we interviewed a faculty memberRoland - to discuss how he had worked together with the LAs and leveraged their expertise in a variety of ways. Roland has taught P-Cubed several times but was not involved in its original curriculum development.

We interviewed three LAs for the investigation presented here, though the three we focus on were selected among five interviews. We chose these three LAs because they portrayed the deepest reflection on their experiences and were able to articulate their relationships with the feedback mechanism with nuance and clarity. We attribute this distinction in part to the iterative development of the interview protocol, which did not give the first two interviewees (Alvin and Bella) as much of an opportunity to discuss their feedback writing. The latter three (Carly, Derek, and Erica) were also all seasoned LAs with multiple semesters of teaching experience to reflect on, which has provided them with multiple, variegated perspectives on what the feedback means to them and how they have helped the mechanism develop over time. For these reasons we present the perspectives of Carly, Derek, and Erica. Carly is a biosystems engineering major, who at the time of her interview was finishing up her fifth semester as an LA. Derek was a LA for seven semesters, and he recently graduated and entered the workforce as a mechanical engineer at a large manufacturing company. Erica is a physics major who was a P-Cubed LA for four semesters and, at the time, was finishing up her second semester as an Electricity and Magnetism P-Cubed (EMP-Cubed) LA. All three LAs are white, as is Roland. We treat the interviews as individual anchor points [33] through which we can understand how LAs came to perceive and influence the feedback mechanism during their time in P-Cubed.

\section{ANALYSIS AND FINDINGS}

Our research questions were asking (i) Has a community of practice developed around LAs in P-Cubed? (ii) How has the practice of feedback been shaped by P-Cubed LAs? (iii) How can the LAs' influence be characterized as a student partnership and what characterizes this partnership and its outputs? In this section we will outline our findings with respect to this focus. First, we will demonstrate how the LAs comprise a community through which new LAs can learn from older ones and master teaching practices (specifically feedback) that P-Cubed LAs have taken ownership over. Second, we will show how the LAs have taken ownership over the practice of feedback writing and developed and changed it in a way that is aligned with LAheld values and experiences. Third, we will show how the LAs have come to occupy influential positions within the P-Cubed instructional staff and how they have forged an effective partnership with faculty in a way that gives them influence on how the course is run beyond just normal LA duties.

\section{A. The learning assistant community of practice}

The first main finding was that the LAs experienced a learning trajectory within P-Cubed that resembled attainment of central membership in COP. Specifically, we found that LAs make up a community in which new LAs learn from older ones and hone their teaching skills, eventually taking on the roles of veteran LAs in a cyclic fashion. In Sec. I, we demonstrated how the design of the course was primed for a community of practice to develop, and here we will show that it has actually developed. Since design decisions do not guarantee the development of a community of practice, this finding serves as evidence that the design principles in P-Cubed [30] did in fact lead to a community of practice developing among the LAs in the course. The LAs share the joint enterprise of teaching this course, along with a shared repertoire of course materials, problems, experiences, and training. Additionally LAs are continuously engaging with one another (mutual engagement) through weekly pre- and postclass meetings. More importantly, we see that LAs experience a learning trajectory in the community. This process, as we will 
demonstrate, begins with being a student in the class, and develops over time as a student is recruited into becoming a LA, and as that LA learns to hone their practice and exert their own influence and perspective on how the course is run.

When we interviewed Roland about his teaching experience with LAs, he described this process in detail. He started by talking about what it is like for new LAs to adjust, which is an important step that new members of a COP go through when learning to take up practices at first.

"They come in and they worry about a lot of things. And they can then consult somebody who isn't, some guy that's like their dad's age or older. They can talk to somebody who's their peer about strategies for going through things. I mean, it's one thing for me to tell them...it's another thing to have somebody who they see as their peer say, 'you know, this actually does work if we try this'...not necessarily how I'd want to approach an issue, but [the older LA] might have tried things that might have worked better for them." (Roland interview)

He first talked about how it is easier for new LAs to learn from and consult other LAs as opposed to Roland himself, who said he's probably older than their dads. He highlighted this connection between peers that might be more automatic and comfortable for these newer LAs, which puts the older LAs in a perfect position to provide initial guidance into what it means to teach as a P-Cubed LA. This is aligned with the COP idea that newcomers learn best from more senior members of the same community [3]. Roland also mentioned how LAs might provide suggestions that do not necessarily match up with how Roland would "approach an issue," but he acknowledges that this is a plus, because veteran LAs will have ideas about what worked for them, to which a newer LA would likely relate much better than they would to Roland. This is also in line with the idea that LAs learn from LAs in the P-Cubed LA community of practice.

Roland also talked about how he noticed LAs helping each other out in a variety of settings, like meetings and outside of school. One skill he said LAs learn is how to help each other out with teaching duties. He commented on the disproportionate benefit it made when older LAs exemplified this skill as opposed to Roland simply articulating it.

"I'd try saying this, 'Try relying on your, your fellow LAs.' But when you have senior LAs... who were so willing to do this and so willing to go out of their way and help the other LAs in the class, it was contagious." (Roland interview)

Roland highlights how the senior LAs model the behaviors that he wants to suggest to the new LAs, and by doing so, they set the norms for the group. It was almost as if Roland's mentoring duties as the faculty instructor were superseded by the "contagious" behavior of veteran LAs who already exemplified what Roland hoped the new LAs would learn to do. Rather than Roland teaching the new LAs, it was the LAs who taught one another how to do the practices of their student-instructor community. Again, we see older LAs guiding the learning trajectory of community newcomers and how LAs are able to mutually engage as a community.

The LAs themselves were also aware of their central role in maintaining the community of LAs and their take-up of teaching practices. In reflecting on this process via email correspondence, Erica provided an example of what this community process looks like on an everyday basis. In Fig. 2, we show a screenshot that Erica took of a conversation with a fellow TA about how to polish a feedback to be given to PCubed students. This occurred after Erica had been teaching for seven semesters (as an LA, and newly as a TA) and her peer was a first-semester newcomer to the teaching staff, which means this interaction offers a snapshot of the community that exists across student instructors with varying levels of experience.

In the exchange, Erica, writing in the blue text bubbles on the right-hand side, provided some lighthearted comments about how to reword several sentences that the other TA (words in gray on the left) had sought her advice on. It is obviously a friendly exchange as there are many exclamation marks, laughter typed out in all caps, and use of emojis throughout the message. Erica and this other instructor clearly have an easy rapport both as friends and fellow teachers. This provides insight into what relationships between LAs can look like in the P-Cubed community. As evidenced by the personal text message, the connections between LAs go beyond classroom exchanges, and many see one another as friends and confidants. From a COP perspective, this extends the boundaries of the community, and allows its members more opportunities and places to share practices and help one another improve, such as through texting.

When we compared the feedback written by LAs with the perspectives they provided in interviews, we found confirmation that the LAs accumulated expertise as they moved up through the P-Cubed LA community. In Carly's interview, she recalled how feedback she had received as a student in P-Cubed helped her maintain confidence as she went through the course for the first time. Specifically, she highlighted how balance can be helpful by talking about how criticism can be connected to praise in ways that made it easy for Carly to see how she could improve.

"One thing that I found - I think that I usually found the most helpful was when the positive thing that was being highlighted was connected as well to the thing that I needed to improve on, because then that gave me a clearer idea going into class of, 'okay this is one thing that I'm going to focus on today." "(Carly interview) 


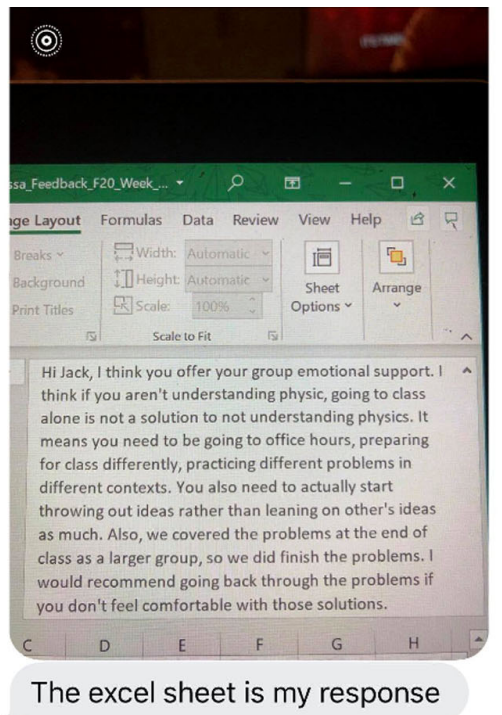

AHAHAHHAHA

alright so the "It means..." sentence

can be worded like "It means taking

up options like..." rather than the

'need to be', which gets rid of

confrontational messaging

then the "You also need to actually

start..." sentence can begin more

like "This will be supported by you

offering more ideas rather than.."

the "Also, we covered..." sentence

could be more like "The solution to

the problems isn't the main goal;

we're looking more to see you

understand the fundamental

concepts than reach an answer."

the rest of it seems good!!

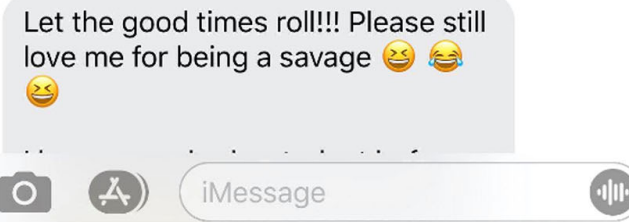

FIG. 2. Text exchange between Erica and a TA, exemplifying strong relationships within the student teaching staff of P-Cubed. The blue bubbles on the right show Erica's suggestions for the TA's feedback, while the gray bubble on the left shows the TA's response to Erica's suggestions.

The reason we bring up this experience is because it demonstrates how Carly was thinking about what was and was not helpful about the feedback from an early point in her LA trajectory, even before she began constructing feedback herself. By design, new LAs are recruited from the set of current and former P-Cubed students in part so that they can draw from experiences such as these. Carly's experience is proof that the learning trajectory of LAs can begin when they are still students. Specifically, she was learning to construct feedback even before she became an LA, which indicates that non-LA students can exist on the periphery of the P-Cubed LA community just like Carly did.

In reading through excerpts of feedback written by Carly, we found several instances of balancing praise and criticism. One instance is provided below.

"You showed a lot of initiative and did a good job of getting the group started on working on the problem. I liked that you were thinking out loud and talking through your work as you did it. However, there were several times where the entire group was not on the same page or were not fully understanding what you were working on." (Carly feedback)

Here, Carly pointed out that the student was promoting work within the group, which was good, but the group members did not have a strong understanding, which was what needed to improve. She tied the improvement to an already somewhat productive activity that was happening within the group, thereby highlighting the connection between her praise of the group and her suggestion for improvement. Her usage of this strategy and her acknowledgement of its helpfulness in her interview show that her feedback practice is connected to her earlier experiences. This strengthens the idea that students like Carly can find themselves on the LA learning trajectory even before they are officially hired as LAs.

To show another example of what this trajectory within community can look like, we also demonstrate how Derek gained expertise and used it in practice. During Derek's interview, he provided a detailed look into a time when feedback helped him improve his group work and start buying into the class when he was a student in P-Cubed. The feature that he found so helpful was that the suggestions in the feedback were justified. His instructor was trying to get Derek to interact with his group more and generate discussions.

"'You need to incorporate discussion with your other group members, because the goal of this class is to work as a group, and you won't be able to solve the problem and you won't be able to get your understanding better unless you start conversing with those other group members.' That was at the very beginning of the class, and that helped, because once I started conversing with my other group members... it actually created a better environment in our group, kind of almost trust, like 'alright I know that you're asking this question about why I think it's this way because that's what we do in the class." " (Derek interview)

The instructor suggested interacting more with group members during class. What stuck with Derek was the fact 
that this interactive theme was aligned with the goals of the entire course. Derek used this same justification to normalize question asking within his group, and he says this process led to "a better environment in our group." There are two main takeaways from Derek's reflection: (i) Derek learned the importance of justifying critique in feedback, which was a major step for his trajectory as a feedbackwriter in the LA community. (ii) He realized the importance of group work in P-Cubed, which led him to improve his own group work. This is a key skill among members of any community of practice, who collaborate frequently on mastering practices.

In reviewing the feedback written by Derek, we saw the same commitments carried out. Below, Derek encouraged a group of students to work together instead of waiting for Derek to rescue them.

“Listen to each other's ideas, don't just wait around for me to give you the answer because if you aren't making an attempt to work with each other, I'm not going to be much help. I know you can do this because at the end of class Tuesday everyone helped each other when I asked those individual questions. It worked out really well when you all worked together." (Derek feedback)

Derek justified his suggestion by writing that he would not be able to give away answers, which means that the students would need to adopt a better strategy for working together. He referred to a time when this group did work well together, and used it to back up his reasoning in the feedback. In this example he is passing on and modeling practices that he came to value-justifying critique and working together. This is Derek's way of extending an opportunity to take up the learning trajectory that many LAs and P-Cubed students have taken before.

Another nod to Derek's high view of group work came during an interview comment when he was reflecting on what it was like to be a P-Cubed student. In particular, he found it helpful to get others involved and ask questions. These practices align well with his previous commitment to "start conversing" with his group.

"Getting everyone involved, and asking questions... I valued those behaviors before I became an LA, because when I would not do those behaviors, I would be like, 'I'm struggling in this class right now,' and when I would do those behaviors, I would go, 'This class is really easy.' " (Derek Interview)

Again, Derek discussed how he learned to conduct himself in certain ways in order to be successful-e.g. "getting everyone involved" or "asking questions." It came as no surprise to see elsewhere in Derek's feedback statements like, "take a step back and talk to your group," "ask questions about what you are missing," and "if you aren't making an attempt to work with each other, I'm not going to be much help." The suggestions he provided in his written feedback stand parallel to the behavior he adopted as a P-Cubed student and LA. Like Carly, this points to a cohesive learning trajectory that Derek followed as he learned to construct feedback as a P-Cubed LA. Each trajectory began when they were students in P-Cubed, where many of the practices important to the LA community are reflected in student-centered group work. This dual experience points also to a shared repertoire of practice that LAs develop beginning with their time as students in P-Cubed.

We have argued that the LAs operated within a community of practice, and more specifically that they underwent a learning trajectory as they progressed from P-Cubed student, to new LA, to veteran LA. An important part of this process was the sense of togetherness, because the LAs learned through their relationships with one another and their past experiences within P-Cubed. Because of this closeness, they collaborated on many teaching efforts. Roland had a keen eye for how this community came together while he was an instructor.

"[A senior LA] helped foster a willingness among the LAs to help each other... a willingness to say, 'let's help each other.' Because sometimes some of the other LAs might have a solution and they rely on each other like that and that was really nice." (Roland interview)

In this comment he described how a senior LA used her relationships with the other LAs to encourage them to help one another with teaching issues or when a solution to a problem needed to be shared. From the COP perspective, this togetherness shows how members of the community leveraged their relationships to build a shared repertoire of practices. In this excerpt and throughout this section, we see community as the source from which LAs learn to grow and improve their teaching.

Another way to conceptualize the trajectory towards central membership in the P-Cubed LA community is by considering the student body of P-Cubed as its own community from which a pathway leads to the LA community. Roland commented about the preparation LAs go through as P-Cubed students.

"They know the environment. They know the community of the class. They know how the students within groups can interact...I think it just makes for a good community of learners. And the LAs having done that-I think that also helps them help each other as they teach the class." (Roland interview)

The feature he highlighted was the communal aspect of being a P-Cubed student. They learned to help each other and collaborate as students, which is a practice that continues to help them as they work together on teaching the class. He went on to compare the enterprises of each community: learning science and teaching it. 
"The P-Cubed community is like, 'how do we do science?' ...While science educators [are like], 'what do we do as we teach science?' We sort of can follow the same model: what works, what doesn't work. We collaborate with each other. And I think it does transfer." (Roland interview)

He again highlighted the collaborative aspect of each endeavor and capped the discussion with a reiteration that he "think[s] it does transfer." From a COP perspective, Roland is pointing to the brokerlike nature of being a PCubed LA. Mastering science practices together as students builds co-working skills_-skills that new LAs have already learned to excel at when they first step from studenthood into the LA position. This sets them on a course towards the center of the LA community just like the LAs who came before. It is notable to mention here that Roland did not participate in the curriculum development process for $\mathrm{P}$ Cubed, which further highlights that the class is seen as a community even by those who did not design it into the course.

Through these quotes, we have provided evidence that there is a community of practice among the P-Cubed LAs. They share the joint enterprise of helping their students develop scientific practices and group work skills, and they learned to achieve these goals by collaboratively figuring out best practices (or in COP speak, developing a shared repertoire through mutual engagement). The existence of this LA community is owed in part to the learning trajectory that LAs take as they move from students to senior LAs in the course.

\section{B. Development of feedback practice}

The second main finding was that the development of feedback practice among LAs resembles the evolution of practice in a community of practice. In Sec. VA we established the existence of the community of practice and the LAs who participate. We dissected how Carly balanced praise and critique in her feedback and how Derek leaned his feedback into group work and justified his critiques. These were presented as evidence for the learning trajectories and memberships that Carly and Derek have traversed and held within the LA community. Additionally, when analyzing LA interviews and feedback excerpts, we noticed that the LAs had iterated on what feedback looked like compared to its original presentation in the course materials in subtle but important ways. In this section, we will show in greater detail how these LAs have developed the practice of writing feedback. This influence on a practice in the community exemplifies how LAs participate in negotiating a joint enterprise, which is an important part of any community of practice. It is a process that captures the trajectories of whole communities, because it indicates how a community's goals are changing.
Before we dive into what feedback has evolved into, we look to how it began. P-Cubed has been offered every semester since Fall 2014, which means it has undergone six years of iteration in its teaching. Its original developers penned a guide for constructing feedback, and one of the course's original developers and instructors (Irving) is still involved in the training of LAs. His influence through the course materials, the LA training, and the management of LAs is important when considering how the course has evolved. To see what the course materials look like, we have analyzed the assessment guide meant to be used when LAs provide grades of in-class work alongside the written feedback.

When describing how students will receive feedback, the assessment guide provides structural details that students can expect to see. Based on their in-class performance, students receive a numerical grade with written commentary that outlines something positive they did, something to work on, and a suggestion for improving their in-class work.

"You will be provided with written feedback before the start of your next project based on your performance on the previous week's project that will focus on one type of participation that you excelled at and one area we would like you to work on in the next project and suggest how you might go about doing that." (Assessment guide)

This same structure is rephrased during a presentation to LAs at the beginning-of-semester training. Again, we see praise, a critique, and a strategy for improvement.

"Feedback has two parts: How did the group do? How did the individual do within the group? Each part addresses three things: (1) Something the student or group did well, (2) Something to work on for next week, (3) A strategy for how to work on it." (Training presentation)

The training presentation further clarifies the structure of feedback; there is an explicit instruction for LAs to write feedback that addresses both the group and the individual. We refer to this portion of the feedback practice as "reified" because it is what has been baked into the materials that have withstood cycles of LAs and in part guided the take-up of LA teaching practices. We represent the feedback and its reified components (as portrayed by the instructor-designed materials) in Fig. 3. Though this does not capture the LA perspective, it provides a starting point which will make it easier to show how the LAs elaborated and filtered the feedback mechanism in various ways. When the course was conceived, this reified feedback represents a snapshot of the original "enterprise," upon which the LAs negotiated their own goals and best practices when they wielded influence within the community. 
First paragraph, to group:

$$
\begin{aligned}
& \text { a praise of in-class work } \\
& \text { a critique of in-class work } \\
& \text { a strategy for improvement }
\end{aligned}
$$

Second paragraph, to individual:

$$
\begin{aligned}
& \text { a praise of in-class work } \\
& \text { a critique of in-class work } \\
& \text { a strategy for improvement }
\end{aligned}
$$

FIG. 3. The feedback structure described in the course materials is two similarly structured paragraphs focused on in-class work by the group and the individual.

To show how LAs have played a part in making feedback their own, we begin by reframing the formative experience from the previous section that Carly talked about in her interview. She asserted that balancing and connecting praise and critique was important to her when writing feedback. The emphasis on connection is not part of the reified feedback, but it was part of Carly's P-Cubed experience. She specifically remembered receiving a piece of feedback that helped her come to this viewpoint.

"There was one week where the positive was essentially like, 'You do a good job of facilitating discussion within the group and asking people to pause and clarify what they're saying' ...but then the follow-up was, 'Sometimes though, you save questions for me as the instructor when you could be asking these questions to your group." " (Carly interview)

This clues us further into how Carly sees the balancenot just as a tally of positives and negatives, but in a connected way, where the suggestions fit in alongside things that the student is already doing well. In reading through excerpts of feedback written by Carly, we found several instances of balancing and connecting praise and criticism, such as the excerpt in the previous section.

Another piece of feedback that Carly wrote exemplified this connective balance that she was committed to providing for her students.

"You do a great job of working through the math problems that are involved within these problems and I can tell this is an area you are comfortable in. If I had one recommendation for you it would be to leave your work in variables for as long as possible." (Carly feedback)

Carly used the same strategy as before. She praised a student for her proficiency with math and then suggested a further improvement to use variables more often. Carly's experience about feeling reinforced by this connective balance was reflected in how she wrote feedback. The connection between the positive and room-for-improvement aspects of the feedback was never outlined in the assessment documents or discussed in the LA training around feedback. This connection, although a subtle change, does significantly transform the direction of the feedback as being targeted around one theme or practice as opposed to a divergent emphasis where positive and improvement aspects are split in focus. Currently we have no way of evaluating whether a concerted focus or split emphasis will have more of an impact on the students, however, this is not the focus of this paper. Instead Carly, based on her experiences and what she believes to be beneficial, has added to the feedback approach by deciding on the need for connectivity. In this way, she was able to redirect the enterprise of the feedback practice within the LA community.

When examining Derek's and Erica's feedback, we found similar patterns despite not hearing about experiences from studenthood that reinforced this feedbackwriting strategy. For example, Erica's feedback to one student highlighted his strength of putting in most of the group's effort alongside a caution that he should encourage other group members to try out their own ideas.

"You had many equations and drawings in front of you, something that your group needed a lot. Don't let yourself be the only one doing this, however, because it seemed like your group was starting to become reliant on your work to get them through the problem...If you see yourself being the only one doing writing or calculating, stop and ask your group members what they think." (Erica Feedback)

She connected the praise-supported his group by creating physics representations in front of him-with the critique of suggesting that he encourage other group members to take the lead sometimes. If Erica learned this connection strategy from Carly rather than from her own experience with feedback as a student, then this suggests that LAs in P-Cubed are learning to write feedback from both (i) their experiences as students and (ii) their collaboration with one another. Even the instructor who provided feedback to Carly years ago was diverging slightly from the explicit, reified instructions in the course materials. This suggests a gradual shift in how feedback is given in PCubed - the strategy of connecting and balancing was already somewhat in practice when Carly took the class based on the feedback she was given but never formally reified. Carly has now emphasized and centralized its importance and given her level of experience and centrality to the LA community has likely instilled it in other students and LAs. This aligns with ideas from COP that would suggest LAs learn practices in concert with other LAs but also act as brokers who may transfer practices or values from outside the community. 
A second feature of feedback practice that we analyze here is the written justification of critique. In the previous section, we demonstrated Derek's commitment to this practice. When we examined notes taken during a discussion among LAs at training, we noticed that older LAs tended to suggest taking up this practice, despite its absence in the course materials: "Justify why you are asking them to do something," "Make sure you mention why their grades changed if they did" (LA discussion notes). This focus on putting justification in the feedback is something that all interviewed LAs agreed on. The fact that it surfaced during LA training in discussions between LAs but not at all in the course materials suggests that this feature of the LA-filtered feedback has emerged primarily from experience rather than course design.

We can point to Derek's feedback excerpt in the previous section as a prime example of critique being justified. An explanation for this commitment could be that LAs feel that they have less authority than graduate TAs or faculty instructors, leading them to justify the feedback they give to their students as a way to build credibility. Below we showcase some examples of how Carly and Erica provided justification in a similar fashion to Derek.

For example, Carly told a student to use variables instead of numbers when doing math.

"Leave your work in variables for as long as possible. By only putting numbers in at the very end, you will make it easier to catch simple mistakes and to add in other variables as needed. This will also help you and your group to see the connections that there are between various variables and equations." (Carly feedback)

The suggestion Carly gave was backed up with reasoning. Carly wrote that using variables would make it easier to catch mistakes and see connections when carrying out the math. Her feedback demonstrates a commitment to telling her students why a suggestion is being given.

For Erica, too, the feedback she wrote for her students exhibited a deep commitment to providing her students with reasoning for her suggestions. Below, she wrote to her group about going through the problem-solving process a second time.

"Take some time to explain the methods of what you've all done so far before I come ask. It's beneficial to do this because sometimes, the methods you all come up with are not structurally sound or use equations that aren't relevant. Sometimes, the group needs to hear someone repeat what they've done so far as well because someone may not have been following along. Hearing it repeated back can reveal the parts of it that don't make sense." (Erica feedback)

Her suggestion is simply, "take some time to explain the methods of what you've all done so far," but the feedback is far richer because Erica wrote several ways that this can be a helpful strategy in class. One of the hallmarks of Erica's feedback was these lengthy justifications for her suggestions, which left no ambiguity around what Erica was trying to tell her students in the feedback and just as importantly why she is making the suggestion.

For all three LAs, justification of critiques was a core feature of their feedback. This feature of the LA-perceived feedback does not appear to originate from the course materials or training presentation. The LAs have chosen to adopt this feature because of their own experiences and values. The fact that they value justification so much suggests that the LAs have altered the feedback structure from its original form. The fact that they have shifted practice like this suggests that LAs truly have central membership in the PCubed instructional community, because they have made the step from learning to take up practices to dictating how those practices are carried out from the highest level.

When we emailed the LAs to circle back to this theme of developing feedback, Erica provided an explanation for how she evaluates her own feedback-writing practice.

"There is never a perfect way to have written feedback for a student. Knowing that helped me realize that as long as it's not daunting for the student to read and it conveys the message I want them to hear for the week, then I'll know I've written 'good' feedback by my standards." (Erica email)

By evaluating her feedback against her own standards, Erica expressed a part of the agency that P-Cubed LAs have when carrying out their teaching practices. Though Erica was likely guided by course materials, training, personal experiences, and her fellow LAs, she emerged with her own criteria for her feedback. This is what P-Cubed was designed for, and it is why we claim that LAs in this context have had their own, real impact on feedback practices while still remaining grounded in the relevant community and its traditions. The iterations that the LAs have made to the feedback mechanism can also be viewed from the perspective that the LAs are identifying crucial gaps in the curriculum design that need to be filled and are filling them. The need of providing justification with feedback seems abundantly apparent and yet it was never formalized in the training or documentation for the class. It is contributions like this to the curriculum design of the class that leads us into our next finding about SAP.

\section{Learning Assistant influence through student partnership}

The third main finding of the paper is that the LAs in PCubed function as the student end of a student partnership. Because student partnerships are defined largely along the relationship between students and a faculty member or university official, we foreground our interview with 
Roland in this section, where he discussed his perspective on his relationship with LAs when he taught P-Cubed and what he thought about the influence that LAs had. Since we saw in the previous section that the LAs have had significant influence on the practice of constructing feedback, we now explore how this partnership functions. We will show below that the breadth of LA influence extends even further and suggests that the LA community of practice in P-Cubed could be a model for employing students (or LAs) as partners in curriculum design. In order to demonstrate that a partnership centered around curriculum design is at work, we will show that LAs have a strong level of control over decision making on curriculum and pedagogy in P-Cubed. This control is particularly important for a specific type of partnership: curriculum design and pedagogic consultancy, which requires significant participation and say-so from LAs [2].

From Roland's interview, it is clear he learned early on how useful LAs could be to a lead instructor's decision making. He reflected that he learned to rely heavily on LAs for running the course, in effect forging a partnership that gave LAs power as instructors that had major influence on feedback practice, teaching practice, and shaping the LA community. In his own words, "I think [LAs] bring a lot more to the class than any single instructor could possibly bring to the class, in all those different experiences" (Roland Interview). In talking of the different experiences, Roland was referring to the in-class experience LAs have as P-Cubed students before they become LAs and also the experience of accumulating expertise over several semesters of teaching.

The partnership that Roland went on to describe applied more so to the veteran LAs than the newer ones. From his perspective, these seasoned LAs were often better suited to teach than the graduate TA assigned to the course.

"[The graduate TA] hasn't done that teaching in that type of an environment before. And if we get an undergrad LA, who has taught the class once before and was a student in the class once before, they tend to be better than first-time grad students doing the class." (Roland interview)

In making this observation, Roland referenced the environmental preparation that LAs have, which makes them ideally suited to teach P-Cubed as instructors. We provide this quote to show how Roland, as the faculty instructor, views the LAs - to him their teaching expertise is second to none. This quote also highlights that Roland also views the LAs as more experienced members of the community than graduate students, even though they may have more content knowledge in the subject or years in the physics community. This sets up the partnership that Roland allowed to flourish by giving the LAs more responsibilities than would normally be expected from undergraduates.
The LA influence on teaching practice was most apparent when Roland described the role that senior LAs took up in his most recent semester of teaching P-Cubed.

"I see the more senior LAs as being responsible for the day-to-day running of the class...they've done the class multiple times and they've seen a lot of the different issues and things you could run into." (Roland interview)

Again we see Roland elaborating on the preparation these LAs have had by running into the same problems many times. He saw them as co-managers of the course, and entrusted them with responsibilities that he would not be able to oversee, because he knew they were experienced enough to tackle issues on their own. This is one of the ways we are seeing the LAs have a level of control over pedagogy.

One of the day-to-day runnings that he entrusted to LAs was twice-a-week meetings to prepare for class. The meetings were held in separate groups to accommodate scheduling, and one set of meetings was led by a senior LA. Roland recalled how she used probing questions, which he saw as reinforcements of good teaching strategies.

"She did a nice job of breaking down the problems and making sure everything that we might conceivably run into in class was covered in these pre-class meetings, and asking and modeling good probing questions for the junior LAs...she did a really good job of modeling what good interactions with students would look like." (Roland Interview)

By Roland's account, these meetings were better for having been run by this LA. Not only that, but she was able to model student interactions, implying that she had an indepth understanding of how students might approach the relevant problem. By letting a LA take up a position of power like this behind the scenes, Roland allowed for the LAs to take up central positions in the instructional staff as a whole. This had the dual effect of leveraging LA expertise to improve teaching practices across the whole staff and also encouraging a framing of P-Cubed instruction that centers LAs, which could be seen by old and new LAs alike. Even the LAs who did not have these bigger responsibilities could see that the partnership was at work.

The P-Cubed students also bore witness to this elevation of LAs because during class time, Roland's classroom was run by the same senior LAs that he talked about earlier in the interview. The way the room was set up put Roland on one side of the classroom. The other side he left to be managed by an LA. He trusted this LA to manage problems that arose among other instructors, and in his interview he commented on the peace of mind he had during class.

"Sometimes what happens during class, [an LA] runs into something and they're unsure how to proceed with 
it. It was nice to have somebody who [LAs] could rely on on the opposite side of the room." (Roland Interview)

The "somebody" he mentioned here was the LA who took charge of managing the class and helping other LAs when hard-to-manage situations arose during group work. In this way, Roland and a handful of senior LAs (of whom one was this classroom manager) forged a partnership where they all had their voices heard and their expertise appreciated in how the class was run. As described by Matthews [4], this quote exemplifies a reciprocal partnership, where students' inputs are truly valued and not tokenized. This is an example in which P-Cubed teaching practices stand on the very top rung of the participation ladder in Fig. 1.

The LAs themselves reflected in email correspondence that they felt their voices were heard on course decisions and how the class was taught. This signifies that these veteran LAs had central influence on the practices of the PCubed LA community, and it was not just Roland's perception. In Erica's email, she reflected on how she gained familiarity with P-Cubed's in-class problems over time, and eventually began making suggestions for improvements that would clear up sources of confusion.

"Over time, I became more familiar with what each problem was made for: each problem had a concept it intended to convey through the story, and as that message became clearer to me, I became more vocal about places that were routinely confusing to me and in what places we could add more context or rephrase things to make them clearer." (Erica Email)

Erica only gave input on problem design after she felt that she had gained familiarity and expertise on what the problems were meant to be about in the first place. This highlights another benefit of having LAs participate in this partnership: their suggestions are grounded in the dual experience of dealing with the course materials from a student perspective and an instructor perspective.

The influence that LAs have in P-Cubed extends beyond the physics problems. In Carly's email correspondence, she discussed how she had an idea to change part of the structure for delivering feedback: rather than providing grades according to a written rubric, she wanted for instructors to input feedback into an app that mapped the rubric into a questionnaire that related more closely to experiences instructors would have in class.

"I think that the professors and actual TAs had a lot of respect for the LAs and what they had to contribute...My ideas were taken seriously and either implemented or I was given clear feedback about why they weren't implemented. One thing that I contributed was a different method for giving weekly grades to students. Although it wasn't implemented long-term, it was trialed for a semester and it felt like I'd been able to move the class forward (even if it was more of a reassurance that the current method was still a good one)." (Carly email)

Carly's app idea ended up on the back burner after a pilot semester, but it remains a testament to the power that senior LAs are granted in steering the teaching practices and feedback practices of P-Cubed. A common concern of student partnerships is that the input from less powerful members (LAs) is sometimes not taken seriously [5]. In Carly's case, her ideas were encouraged until they became full-on transformations of teaching practice and implemented broadly to test their efficacy.

Another, more direct example of an LA participating in decision making around feedback structure was when Erica had a chance to give input to the EMP-Cubed curriculum, which is a P-Cubed-like course that covers introductory electricity and magnetism, first taught in Fall 2017.

"EMP-Cubed was being developed and Paul [Irving] was sitting at a table, thinking about how to implement self-written feedback from students into the course structure. I sat and I brainstormed with him, and my idea of dividing the self-feedback so that it was slowly implemented in stages through the semester ended up being the structure that was implemented." (Erica Interview)

Though the context was not P-Cubed, Erica had forged a partnership with Irving in part from her role as an LA in PCubed. This relationship made it natural for her to provide input on a new course and reimagine what feedback practice could look like. In this way, the LA-faculty partnership had a tangible impact beyond the course where it began.

The last partnership-like impact that we will describe in this section is the roles LAs play when recruiting new LAs to the instructional staff. Roland described in his interview how LAs provide special insight during this process.

"Like halfway through the semester, we'll discuss recruiting new LAs and solicit input from more senior LAs...the LAs might say, 'yeah, the person might ought to be this, but I'm not quite so sure about that.' So we get LAs who would say, 'I think this person would make a really good LA.' And having an LA approach one of the students in the class and say, 'you should really apply for this,' I think that helps with recruitment." (Roland Interview)

He described their input as a solicitation, meaning he has sought out their opinions because he values what LAs have to say about potential applicants. The solicitation is another indication that there was a relationship between faculty and LAs through which Roland felt he could consult the LAs on the future of P-Cubed teaching. When he hears comments like "I'm not so sure" and "this person would make a good LA," this helps him direct the way he thinks about the 
recruitment process, because he knows that many of his LAs know the students much better than he does. He admitted earlier in the interview that he really only gets to interact regularly with $25 \%$ of the class over the course of the semester, which is why he relies heavily on LAs during the recruitment of enrolled students. This reliance points once again to the negotiation of LA control over the course. $\mathrm{He}$ also highlights the importance of having LAs encourage the students to apply, the implication being that students may trust the suggestion of an LA who went through that very same process.

We used Roland's commentary on the helpfulness of senior LAs to show how they had a partnership with Roland wherein they were trusted to manage meetings and realtime in-class issues without the intervention of a faculty or graduate TA. This pointed to the responsibility that some PCubed LAs had, which rendered their class-wide influence akin to Roland's. One product of this LA-based power was that they learned to work together to reinforce learning strategies for their students. As Roland recalled, LAs would identify broad needs in the classroom and work with their students via feedback and in-class teaching to help them improve along those lines.

"Trying to reinforce [strategies], not just in feedback, but sitting down at the table with their students face-toface and reinforcing in two ways. You'd have multiple LAs sort of reinforcing the same types of strategies...I think it just organically happened like that." (Roland interview)

Because of how LAs worked together and collectively had influence over a large number of students, they were able to impact in-class teaching and learning in a big way.

We also analyzed Erica's journey with P-Cubed problem design: first learning to do the problems and gaining familiarity, and eventually providing feedback on sources of confusion and improving the LA solution guides. She seized similar opportunities to contribute to exam problems and homework, which she elaborated on via email.

"I wrote exam problems fairly regularly since the beginning of my LA time, even up until now. It feels like having a voice, because my ideas are directly implemented in something a student receives and gets a grade on. Same thing for homework, like deciding my own help room hours or choosing how I can run those hours. It's like a real-time judgement call." (Erica Email)

She viewed these opportunities as "direct implementation" of her ideas onto the materials a student would go on to use. An area where she had total control was her "help room hours" where students would come to get help on homework, concepts, or studying. Erica was able to recognize the ways she could leverage her strengths and have the most impact as an LA. She put it very poignantly in her reflection, comparing this impact to a historical, indelible influence on the trajectory of P-Cubed.

"It's sometimes scary, but it also feels very satisfying knowing that I'm putting a little bit of myself in the history of the class." (Erica Email)

Overall, we see many features of the course that demonstrate how these LAs have become central members of the instructional community alongside the faculty instructors and graduate TAs. Through the course design and the compliance of past instructors, LAs have been given responsibility for managing students, opportunities to run meetings and shape the LA community through recruitment, and in some cases seats at the table of curriculum development. And through these myriad opportunities, LAs have stepped up. They ran the meetings, they shaped and sustained the community through mentoring among their ranks, they took responsibility for carrying out teaching practices in accordance with their experience, they grew the community through recruitment, and they passed on these responsibilities to their protegé LAs. The existence of the opportunities listed above and the strength with which the LAs have used these opportunities to wield control of the course are how we demonstrate the existence and characterization of a student-partnership among the PCubed LAs.

\section{DISCUSSION AND CONCLUSION}

The goals of this investigation were (i) to demonstrate the development of a community of practice among P-Cubed LAs, (ii) to describe LAs' influence on the development of a specific practice (feedback) within that community, and (iii) to demonstrate and characterize the partnership between P-Cubed faculty instructors and LAs. Though our first and second findings could be described as "outputs" of the partnership, we presented them separately to motivate the third finding and demonstrate how the partnership functions in a more detailed manner.

This study highlights two specific design principles that encouraged the development of a community of practice within the P-Cubed context: the feedback mechanism and the P-Cubed LA program. According to Irving et al., [30], the feedback was designed to build trust between LAs and students, offer explicit suggestions for improvement to help students take up scientific practices, and legitimize student behavior when aligned with the goals of the class. The LA structure was designed into P-Cubed as a way of providing a social "bridge" into physics, because LAs can be seen both as experts and peers. In this way LAs were designed to be central members of the classroom community. As we showed in our investigation, these design principles successfully set up a community of practice among LAs in a way that allowed P-Cubed students to follow a trajectory 
from physics newcomer to veteran LA. Although this study does not explicitly investigate the student (pre-LA) part of the trajectory within the P-Cubed community of practice, the reflections on the journey from student to LA from our participants do highlight that their student experiences played important roles. This supports the notion that designing for the development of a community of practice can be a fruitful way to orient a classroom. For P-Cubed in particular, the LA program is a significant part of the manifestation of the COP design.

For our context, an important part of the communitybuilding process is that all the LA applicants are previous students from P-Cubed. Although it is somewhat typical for undergraduates to be recruited to be LA's for classes they have taken, our study indicates that this style of recruitment is essential for the P-Cubed LA program. It provides significant preparation for potential new LAs, who often join the staff ready to operate in the collaborative P-Cubed environment. Our LA interviewees often recalled how formative student experiences played into how they went on to teach. Roland, too, commented on how he believes LAs in P-Cubed are very well prepared for their role because of their familiarity with the material.

Another benefit of drawing from the P-Cubed students as an applicant pool is that existing LAs get to participate more authentically in recruitment. This feature in particular is a benefit to the community, because LAs get to have a voice in who becomes more central to their community. They do this by providing first-hand feedback on the character and preparedness of potential new LAs based on their interactions with the applicants as students. If applicants came from outside the class, the existing LAs would not have the personal relationships to draw from, and therefore would not get to participate in community management as closely. The COP framework has an apprenticeship undertone to its set up, and LAs having a voice in the recruitment process allows them to choose the next set of apprentices that they want a hand in guiding. This allowance reinforces to the LAs that their voice matters in regards to the running of the class and maybe more importantly who becomes more central members of the community. However, input on recruitment has to be managed carefully as the culture of the community needs to place an emphasis on whether potential LAs are demonstrating aptitude in the practices and values of the class and not letting a creep towards a recruitment of LAs who are "similar" to them. For recruitment for the P-Cubed LAs, the LAs will encourage students to apply and highlight potential candidates that align with the community, as Roland described, but there is still an application form and interview process supervised by the course coordinators before any formal offer is put forth. This ensures that an emphasis is placed on creating an inclusive community within the P-Cubed classroom and maintaining the goals of the community (joint enterprise).
Despite the tight community that has flourished in PCubed, the COP framework points to new ways it can be improved. In particular, we examine participation and reification. Though LAs have been able to change and direct what practices in the community looks like, their influence on the course has gone un-reified. A prime example of this is in our more detailed exploration on the practice of feedback in Sec. V B. The course materials around feedback still look the same as they did when the course was first offered, despite the many contributions that LAs have made to its structural components when they carry out the feedback practice and mentor other LAs in it. Since the practice has evolved, COP would suggest that these changes should be reified in the course materials and shared repertoire of the community.

Furthermore, the process of onboarding new LAs through mentorship and expansion of the community is still almost completely undocumented in curricular design materials. This is potentially problematic because of the resulting instability around helpful strategies that LAs have introduced into the course. For example, a new program coordinator or a series of new faculty instructors could completely change the enterprise of the feedback-writing practice, solely because of the current enterprise's heavy reliance on participation (without reification). The lack of opportunities for LAs to reify their transformation of the feedback-writing practice is problematic if the goal is to embrace LA-induced change. In order for this community to embrace the directions that LAs appear to be pushing the practice, there needs to be some mechanism in place for LA participation to be reified. Only through the duality of participation and reification can meaning be negotiated by all members in the community. Such a mechanism would strengthen the existing student-partnerships and allow the current LAs to contribute to the reifications of past curriculum designers. This would then better satisfy the system change needed in good student partnerships as outlined by Matthews [4]. In effect, LAs would be able to take part in negotiating and documenting an enterprise that represents the collective experiences and values of feedback writers over time.

Currently, instead of integrating the adaptations formally the class coordinators have instead let the practice of feedback transform organically. Organic transformation versus imposed reification opens up more possible research questions. For example, questions need to be asked about the formalization process - should practices be reified after they reach a level of uniform use by members of the community or is good practice just good practice and should be integrated immediately? One of the realities of curriculum design is that there is no one "right" way to teach. Maybe a level of uniformity being reached in how the LAs teach is an indicator of the utility of a change in teaching practice and a point at which reification should occur. At the very least, the feedback adaptations made by 
the LAs in this study and the lack of reification of those adaptations highlight the need to listen and pay attention to the teaching approaches of LAs as they might just have as much to teach us about teaching as we do to teach them.

One way to address the current issues around reification in P-Cubed would be to update the artifacts that exist in PCubed related to feedback, such as the assessment guide. By incorporating LA perspectives into course materials that would be used in future semesters, we can strengthen the positive influence that LAs have on the course structure. A more explicit strategy would be to administer exit interviews with final-semester LAs that could be incorporated into the materials as a way of preserving their legacy and the improvements that they made to the course during their time. A shadow of this idea exists in preclass meetings, when notes are gathered on the confusing parts of the solution guide, which is then updated for future semesters. These strategies exist to a degree in P-Cubed, but they could be leveraged in other areas of the course and expanded to be a more explicit part of the curriculum development process.

Through our investigation, especially when examining how LAs have developed the feedback mechanism, we demonstrated that in P-Cubed there exists a partnership centered around curriculum design and pedagogic consultancy. In particular, this partnership is characterized by the long-term tenure of LAs and the lasting influence they have on teaching practices. The three tenets of a good student partnership, according to Matthews [4], are at work: (i) Input from LAs is valued among curriculum designers and faculty, meaning the partnership is reciprocal. (ii) All parties benefit from the partnership: LAs who gain experience managing the community and bettering their teaching skills, faculty who get classroom management help and get to learn from peer-learning experts, and P-Cubed students who receive a more personal, relevant physics education. (iii) The outcome of the partnership is broad and sustainable in how it has a lasting effect on the course pedagogy and the structure of the LA community among future generations of LAs.

Fulfilling these tenets is only possible because P-Cubed was structured for LAs to retain a direct influence on the course for years and the LA end of the partnership comprises student teachers, as opposed to just students. The P-Cubed LAs have a special combination of expertise and opportunity, which allows them to influence the course structure in positive, lasting ways. Other curriculum-centered partnerships in publications are markedly different from the P-Cubed model. For example, Cook-Sather [36] detailed a model that utilizes one-on-one student-faculty relationships to reform curricula. The students in this model had not taken the course for which they advised. They instead learned about it by sitting in and gathering observations. LAs in P-Cubed are special because of their closeness to the course, having spent many semesters operating within the course. Also, the existence of a community of LAs helps them build expertise via collaboration, which from a COP perspective makes their advising all the more valuable because it is more likely to be aligned with the values of the course and drawing from a broader selection of experiences.

In another example, Bovill et al., [37] describe how students apply to course design teams for courses they have taken before. In their findings they noticed that the partnerships suffered from significant time elapsed before faculty in the teams noticeably ceded their authority and students felt like they were being taken seriously. In contrast, the PCubed LAs have a long tenure where they build trust with the faculty instructors (who often teach P-Cubed multiple semesters) and with the LA program coordinator (Irving). Their voices are heard semester-after-semester, and taken seriously, as shown in Sec. V C. The features that make the P-Cubed student-partnership unique are (i) the LAs' intimate experiential knowledge of the course, (ii) the community of practice that exists among LAs and influences the course as a collective, and (iii) the tiered nature of the LA community, which allows for more senior LAs to take up significant course responsibilities and make their voice heard on structural decisions without imposing the same pressure on more junior LAs.

In most partnerships, students are recruited directly into partnership whereas in P-Cubed it seems as though LAs gain credibility over time and are gradually consulted more and more on course decisions and given more and more management responsibilities the longer they are a LA with the class. Experience equating to credibility is one perspective but an alternative framing could be that new LAs do not feel equipped or have enough expertise to wield their voice related to group decisions and instead defer to more senior LAs. The intertwined nature of experience and credibility needs to be investigated further in order to understand how a student-partnership borne out of a LA community of practice promotes and restricts the input of the LAs when it comes to curriculum input.

The path towards centrality through experience could represent a more natural progression to include student voices in curriculum development. The way P-Cubed is set up, LAs gain many experiences with teaching the materials and operating within the community before being offered some of the opportunities and responsibilities associated with the partnership that we described. On the other hand, a potential problem with this model is that it privileges voices from more experienced LAs. There is the potential for a form of institutionalization to occur as LAs spend more time teaching the class with the possibilities of their inputs becoming more teacher-centered as opposed to studentcentered. At what point do the LAs stop being students and instead take on more teacherlike perspectives, therefore losing the special influence of student partners in curriculum design? They will never be responsible for the sole 
running of the class but an open question becomes that for this SAP model, when do students become empowered enough that the source of their influence is no longer authentic student experience? This also makes us wonder, what would it look like for new LAs to infuse their voices into the course? We suspect because newer LAs are not as central to the culture of P-Cubed, the course would change faster but perhaps with less overall direction. The inputs of the newbie versus central member is an interesting future direction for SAP research, and we are interested to see research from course contexts that have utilized this more progressive approach to student partnerships.

Overall, this investigation serves as a model for the fidelity of LA-driven student partnership leading to structural changes in a course. The lesson here is that student partnership for LAs is possible and can work well in the case of a course like P-Cubed that has been designed around COP. As we discussed, the features that make the PCubed partnership particularly effective are the features that come from the community of practice that was designed into the course. By learning to teach via the community of practice, LAs gain intimate knowledge of what works and what does not when teaching, they wield collective expertise when collaborating with their peers, and they follow a natural progression towards a place where they have significant influence over the direction of the course. The way this partnership is rooted in the community of practice is what makes it as effective as it is. Reconceiving LA programs as student partnerships opens a path to incorporate students into and reinforce sustainable curriculum change.

\section{ACKNOWLEDGMENTS}

The authors would like to thank our generous participants for their time and openness. For funding the curriculum development and staffing of P-Cubed, we thank the CREATE for STEM Institute at MSU. We also thank the Department of Physics and Astronomy at MSU for funding the hiring and support of LAs. Lastly, we thank Paul Irving's travel fund for funding the publication of this manuscript, and we thank the American Physical Society for a partial fee waiver.
[1] A. Cliffe, A. Cook-Sather, M. Healey, R. Healey, E. Marquis, K. Matthews, L. Mercer-Mapstone, A. Ntem, V. Puri, and C. Woolmer, Launching a journal about and through Students as Partners, Int. J. Students as Partners 1, 1 (2017).

[2] M. Healey, A. Flint, and K. Harrington, Engagement through Partnership: Students as Partners in Learning and Teaching in Higher Education (The Higher Education Academy, York, UK, 2014).

[3] E. Wenger, Communities of Practice (Cambridge University Press, Cambridge, England, 1998).

[4] K. E. Matthews, Five propositions for genuine students as partners practice, Int. J. Students as Partners 1, 2 (2017).

[5] E. R. Sohr, A. Gupta, B. J. Johnson, and G. M. Quan, Examining the dynamics of decision making when designing curriculum in partnership with students: How should we proceed?, Phys. Rev. Phys. Educ. Res. 16, 020157 (2020).

[6] C. Bovill and C. J. Bulley, A model of active student participation in curriculum design: Exploring desirability and possibility, Improving Student Learning (ISL) 18: Global Theories and Local Practices: Institutional, Disciplinary and Cultural Variations (Oxford Brookes University, Oxford, 2011), pp. 176-188.

[7] C. Bovill, The Student Engagement Handbook: Practice in Higher Education (Emerald Group Publishing Limited, Bradford, UK, 2013), pp. 461-476.

[8] A. Flint and M. O'Hara, Communities of practice and 'student voice': Engaging with student representatives at the faculty level, Student Engage. Experience J. 2, 1 (2013).
[9] L. Mercer-Mapstone, S. L. Dvorakova, K. E. Matthews, S. Abbot, B. Cheng, P. Felten, K. Knorr, E. Marquis, R. Shammas, and K. Swaim, A systematic literature review of students as partners in higher education, Int. J. Students as Partners 1, 1 (2017).

[10] V. Otero, S. Pollock, and N. Finkelstein, A physics department's role in preparing physics teachers: The Colorado Learning Assistant model, Am. J. Phys. 78, 1218 (2010).

[11] L. S. Nadelson and J. Finnegan, A path less traveled: Fostering STEM majors' professional identity development through engagement as STEM Learning Assistants, J. Higher Educ. Theory Pract. 14, 5 (2014).

[12] R. M. Goertzen, E. Brewe, L. H. Kramer, L. Wells, and D. Jones, Moving toward change: Institutionalizing reform through implementation of the Learning Assistant model and Open Source Tutorials, Phys. Rev. ST Phys. Educ. Res. 7, 020105 (2011).

[13] E. W. Close, J. Conn, and H. G. Close, Becoming physics people: Development of integrated physics identity through the Learning Assistant experience, Phys. Rev. Phys. Educ. Res. 12, 010109 (2016).

[14] Y. Cao, C. Smith, B. Lutz, and M. Koretskey, Cultivating the next generation: Outcomes from a learning assistant program in engineering, in Proceedings of the American Society for Engineering Education Annual Conference \& Exposition, Salt Lake City, UT (2018 ASEE Annual Conference \& Exposition, Salt Lake City, UT, 2018).

[15] M. S. Sabella, A. G. V. Duzor, and F. Davenport, Leveraging the expertise of the urban STEM student in developing 
an effective LA Program: LA and instructor partnerships, in Proceedings of the 2016 Physics Education Research Conference, Sacramento, CA, edited by D. L. Jones, L. Ding, and A. Traxler (AIP, New York, 2016), pp. 288-291.

[16] J. Conn, E. W. Close, and H. G. Close, Learning Assistant Identity Development: Is one semester enough?, in Proceedings of the 2014 Physics Education Research Conference, Minneapolis, MN, edited by P. V. Engelhardt, A. D. Churukian, and D. L. Jones (AIP, New York, 2014), pp. 55-58.

[17] E. W. Close, J. Conn, and H. G. Close, Learning Assistants' Development of Physics (Teacher) Identity, in Proceedings of the 2014 Physics Education Research Conference, Minneapolis, MN, edited by P. V. Engelhardt, A. D. Churukian, and D. L. Jones (AIP, New York, 2014), pp. 89-92.

[18] R. J. Beichner, J. M. Saul, D. S. Abbott, J. J. Morse, D. L. Deardorff, R. J. Allain, S. W. Bonham, M. H. Dancy, and J. S. Risley, The student-centered activities for large enrollment undergraduate programs (SCALE-UP) project, in Reviews in PER Volume 1: Research-Based Reform of University Physics, edited by E. F. Redish and P. J. Cooney (American Association of Physics Teachers, College Park, MD, 2007).

[19] E. Brewe, Modeling theory applied: Modeling instruction in introductory physics, Am. J. Phys. 76, 1155 (2008).

[20] E. Etkina and A. V. Heuvelen, Investigative science learning environment: A science process approach to learning physics, in Reviews in PER Volume 1: Research-Based Reform of University Physics, edited by E. F. Redish and P. J. Cooney (American Association of Physics Teachers, College Park, MD, 2007).

[21] L. C. McDermott, Physics by Inquiry (John Wiley and Sons, New York, 1996).

[22] D. Caravez, A. D. L. Torre, J. M. Nissen, and B. V. Dusen, Longitudinal associations between Learning Assistants and instructor effectiveness, in Proceedings of the 2017 Physics Education Research Conference, Cincinnati, OH, edited by L. Ding, A. Traxler, and Y. Cao (AIP, New York, 2017), pp. 80-83.

[23] E. W. Close, J.-M. Mailloux-Huberdeau, H. G. Close, and D. Donnelly, Characterization of time scale for detecting impacts of reforms in an undergraduate physics program, in Proceedings of the 2017 Physics Education Research Conference, Cincinnati, $\mathrm{OH}$, edited by L. Ding, A. Traxler, and Y. Cao (AIP, New York, 2017), pp. 88-91.

[24] B. V. Dusen and J. M. Nissen, Systemic inequities in introductory physics courses: The impacts of learning assistants, in Proceedings of the 2017 Physics Education Research Conference, Cincinnati, OH, edited by L. Ding,
A. Traxler, and Y. Cao (AIP, New York, 2017), pp. 400403.

[25] N. Sellami, S. Shaked, F. A. Laski, K. M. Eagan, and E. R. Sanders, Implementation of a learning assistant program improves student performance on higher-order assessments, CBE Life Sci. Educ. 16, ar62 (2017).

[26] H. Jardine, Positioning undergraduate teaching and learning assistants as instructional partners, Int. J. Students as Partners 4, 1 (2020).

[27] G. S. Begley, R. E. Berkey, L. M. Roe, and H. E. Y. Schuldt, Faculty come to appreciate undergraduates as teaching partners in a service-learning teaching assistant program, Int. J. Students as Partners 3, 1 (2019).

[28] F. Daniello and C. Acquaviva, A Faculty member learning with and from an undergraduate teaching assistant: Critical reflection in higher education, Int. J. Students as Partners 3, 2 (2019).

[29] P. W. Irving, M. J. Obsniuk, and M. D. Caballero, $\mathrm{P}^{3}$ : A practice focused learning environment, Eur. J. Phys. 38, 055701 (2017).

[30] P. W. Irving, D. McPadden, and M. D. Caballero, Communities of Practice as a curriculum design theory in an introductory physics class for engineers, Phys. Rev. Phys. Educ. Res. 16, 020143 (2020).

[31] E. Wenger, R. A. McDermott, and W. Snyder, Cultivating Communities of Practice: A Guide to Managing Knowledge (Harvard Business School Press, Boston, MA, 2002).

[32] J. Lave and E. Wenger, Situated Learning: Legitimate Peripheral Participation (Cambridge University Press, Cambridge, England, 1991).

[33] A. H. Dyson and C. Genishi, On the Case: Approaches to Language and Literacy Research (Teachers College Press, New York, 2005).

[34] P. C. Hamerski, P. W. Irving, and D. McPadden, Learning assistants as constructors of feedback: How are they impacted?, in Proceedings of the 2018 Physics Education Research Conference, Washington, DC, edited by A. Traxler, Y. Cao, and S. Wolf (AIP, New York, 2018).

[35] M. Q. Patton, Qualitative Interviewing, Qualitative Research and Evaluation Methods (Sage, Thousand Oaks, CA, 2002), pp. 339-428.

[36] A. Cook-Sather, Teaching and Learning Together: College Faculty and Undergraduates Cocreate a Professional Development Model, To Improve the Academy: Resources for Faculty, Instructional, and Organizational Development (Jossey-Bass, San Francisco, 2011), Vol. 29, pp. 219232.

[37] C. Bovill, A. Cook-Sather, and P. Felten, Students as co-creators of teaching approaches, course design, and curricula: Implications for academic developers, Int. J. Academic Develop. 16, 2 (2011). 